\title{
CORRIGENDUM
}

\section{Rationale and design of the KYOTO HEART study: effects of valsartan on morbidity and mortality in uncontrolled hypertensive patients with high risk of cardiovascular events}

T Sawada, T Takahashi, H Yamada, B Dahlöf and H Matsubara, for the KYOTO HEART Study Group

Journal of Human Hypertension (2013) 27, 580; doi:10.1038/jhh.2013.57

$\begin{array}{lll}\text { Correction to: Journal of Human Hypertension (2009) 23, } & \text { 23. } \\ \text { 188-195; doi:10.1038/jhh.2008.116; published online } 18\end{array}$ September 2008

The authors would like to correct the affiliation of Nobuo Shirahashi, who was included in appendix as part of the statistical analysis organization.

Therefore, the sentence:
'K Yagi, Louis Pasteur Center for Medical Research, Kyoto, Japan; Nobuo Shirahashi, Department of Preventive Medicine and Environmental Health, Osaka City University Medical School, Osaka, Japan.'

Should read:

'K Yagi, Louis Pasteur Center for Medical Research, Kyoto, Japan; Nobuo Shirahashi, Novartis Pharma KK.' 